\title{
Plasma glucose levels as predictors of diabetes: the Mexico City diabetes study
}

\author{
E. Ferrannini • M. Massari • M. Nannipieri • A. Natali • \\ R. Lopez Ridaura $\cdot$ C. Gonzales-Villalpando
}

Received: 11 August 2008 / Accepted: 19 January 2009 / Published online: 18 February 2009

(C) Springer-Verlag 2009

\begin{abstract}
Aims/hypothesis The value of diagnostic categories of glucose intolerance for predicting type 2 diabetes is much debated. We therefore sought to estimate relative and population-attributable risk of different definitions based on fasting (impaired fasting glucose [IFG]) or $2 \mathrm{~h}$ plasma glucose concentrations (impaired glucose tolerance [IGT]) and to describe the associated clinical phenotypes.

Methods We prospectively observed a population-based cohort of 1,963 non-diabetic participants (mean age 47 years), in whom an OGTT was performed at baseline and 7 years later.

Results IGT was fivefold more prevalent (13.5\%) than IFG. In both categories, participants were older, heavier, hyperinsulinaemic, hyperproinsulinaemic and dyslipidaemic compared with participants with normal glucose tolerance. Relative risk of incident diabetes was similar for IFG and IGT categories (3.73 [95\% CI: 2.18-6.39] and 4.01 [95\% CI: 3.12-5.14], respectively), but the population-attributable risk was fivefold higher for IGT (29\% [95\% CI: 26-32]) than for IFG (6\% [95\% CI: 5-7]). Isolated IFG carried no

E. Ferrannini $(\bowtie) \cdot$ M. Nannipieri $\cdot$ A. Natali

Department of Internal Medicine and CNR Institute of Clinical

Physiology, University of Pisa School of Medicine,

Via Roma, 67,

56126 Pisa, Italy

e-mail: ferranni@ifc.cnr.it

M. Massari

National Institute of Health,

Rome, Italy

R. Lopez Ridaura $\cdot$ C. Gonzales-Villalpando

Centro de Estudios en Salud Poblacional and Centro de Estudios

en Diabetes, Centro de Investigacion en Salud Poblacional,

Instituto Nacional de Salud Publica,

Mexico City, Mexico

increase in risk. Lowering the threshold to $5.6 \mathrm{mmol} / \mathrm{l}$ raised the population-attributable risk of IFG to $23 \%(95 \%$ CI: 20-25); its contribution to diabetes progression, however, was largely due to co-existent IGT. In multivariate analysis adjusting for sex, age, familial diabetes and BMI, fasting and $2 \mathrm{~h}$ glucose were independent predictors.

Conclusions/interpretation Fasting and $2 \mathrm{~h}$ glucose values are independent predictors of incident diabetes. Isolated IFG is not a high-risk condition; lowering the diagnostic threshold increases the population-attributable risk of IFG fourfold, but performing an OGTT captures additional diabetes progressors compared with the number identified by IFG.

Keywords Diabetes - Diabetes prediction - Diabetes risk · Impaired fasting glucose - Impaired glucose tolerance ·

Population-attributable risk

$\begin{array}{ll}\text { Abbreviations } \\ \text { IFG } & \text { Impaired fasting glucose } \\ \text { iIFG } & \text { Isolated IFG } \\ \text { IGT } & \text { Impaired glucose tolerance } \\ \text { iIGT } & \text { Isolated IGT } \\ \text { NGT } & \text { Normal glucose tolerance } \\ \text { PAR } & \text { Population-attributable risk } \\ \text { ROC } & \text { Receiver operating characteristic }\end{array}$

\section{Introduction}

The plasma glucose concentration, like many other physiological variables, is a tracking variable, i.e. individual values tend to remain in the same region of the population distribution over time. As a consequence, plasma glucose values are good predictors of incident diabetes. Predicting diabetes has dual value: it provides the evidence basis for 
setting diagnostic thresholds for diabetes (and dysglycaemic states in general) and it suggests pathophysiological mechanisms for the development of hyperglycaemia.

Diagnostic thresholds are defined by convention depending on the kind and level of risk to be prevented. In the case of diabetes, the risk of microvascular and macrovascular complications rises with plasma glucose levels, the relationship being steeper for micro- than macrovascular disease [1]. The current, widely accepted definition of type 2 diabetes uses thresholds for fasting $(\geq 7.0 \mathrm{mmol} / \mathrm{l})$ and $2 \mathrm{~h}$ post-load (standard $75 \mathrm{~g}$ OGTT) plasma glucose concentration $(\geq 11.1 \mathrm{mmol} / \mathrm{l})$ : values exceeding either level are diagnostic [2]. Criteria for lesser degrees of dysglycaemia are less well established. Impaired glucose tolerance (IGT), defined by the $2 \mathrm{~h}$ glucose concentration, carries heightened risk of diabetes [3-5] and, possibly, cardiovascular disease [6-7]. The pathophysiology of IGT is a combination of insulin resistance, hepatic as well as peripheral, and beta cell dysfunction [8] that is similar to that of diabetes, only of a milder degree. As an obvious antecedent of type 2 diabetes, IGT is identified by a screening OGTT, which costs time, facilities and money. More recently, a new category of impaired glucose regulation (IGR, in WHO terms [9]) was introduced to obviate the investment in OGTT screening, namely impaired fasting glucose (IFG), defined as fasting plasma glucose between 6.1 and $7.0 \mathrm{mmol} / \mathrm{l}$. While clearly a risk condition for type 2 diabetes, IFG is believed to have a partially different pathophysiological basis to that of IGT, being characterised by hepatic rather than peripheral insulin resistance and by more marked beta cell dysfunction [10]. Before this definition was widely accepted, it was changed and the lower threshold for fasting glycaemia lowered to $5.6 \mathrm{mmol} / \mathrm{l}$ [11]. Rationale and value of the new IFG definition have been criticised [12].

The present work takes advantage of 7 year follow-up data from the Mexico City Diabetes Study [13], a population-based observational study in a population with a high prevalence of diabetes, to assess the value of categorisation of prediabetic states with respect to incident diabetes. Assessment was done by systematically analysing $\mathrm{RR}$, population-attributable risk (PAR) and clinical phenotype of old and new definitions of IFG and IGT.

\section{Methods}

Participants Data were collected as part of the Mexico City Diabetes Study [13], a population-based survey of diabetes and cardiovascular risk factors. Low-income neighbourhoods in Mexico City were selected and a complete enumeration of these was carried out from November 1989 to October 1992. Among the 15,532 inhabitants of these neighbourhoods, 3,505 eligible individuals (35-
64 year-old men and non-pregnant women) were identified. Of these, 2,282 (1,342 women, 940 men) completed baseline medical examinations at the clinic. Participants with type 1 diabetes were excluded. Type 2 diabetes was classified as a fasting plasma glucose concentration $\geq 7.0 \mathrm{mmol} / 1$ or a $2 \mathrm{~h}$ plasma glucose concentration $\geq 11.1 \mathrm{mmol} / 1$ after a standard 75 g OGTT [13]. Participants who reported having a history of diabetes and who at the time of their clinical examination were taking oral glucose-lowering agents were also considered to have type 2 diabetes, regardless of their plasma glucose values. Diabetic participants on insulin whose age of onset was $\geq 40$ years or whose BMI was $>30 \mathrm{~kg} / \mathrm{m}^{2}$ were also considered to have type 2 diabetes. After excluding 319 type 2 diabetic participants at the baseline examination (196 women, 123 men), 49 and 265 of the remaining 1,963 participants had $\mathrm{IFG}_{6.1}$ (fasting glucose $6.1-6.9 \mathrm{mmol} / \mathrm{l}$ ) and IGT (fasting glucose $<7.0 \mathrm{mmol} / 1$ and $2 \mathrm{~h}$ glucose 7.8 $11.1 \mathrm{mmol} / \mathrm{l}$ ), respectively. Isolated $\mathrm{IFG}_{6.1}$ and isolated $\mathrm{IFG}_{5.6}$ (5.6 $\mathrm{mmol} / \mathrm{l}$ threshold) were defined as $2 \mathrm{~h}$ glucose $<7.8 \mathrm{mmol} / \mathrm{l}$ and fasting glucose between 6.1 and $6.9 \mathrm{mmol} / \mathrm{l}$ or between 5.6 and $6.1 \mathrm{mmol} / \mathrm{l}$, respectively. Isolated IGT, isolated $\mathrm{IGT}_{6.1}(6.1 \mathrm{mmol} / \mathrm{l}$ threshold $)$ and isolated $\mathrm{IGT}_{5.6}(5.6 \mathrm{mmol} / \mathrm{l}$ threshold $)$ were defined as $2 \mathrm{~h}$ glucose between 7.8 and $11.1 \mathrm{mmol} / 1$ and fasting glucose $<5.6 \mathrm{mmol} / \mathrm{l}$ or between 5.6 and $6.1 \mathrm{mmol} / \mathrm{l}$ or 6.1 and $6.9 \mathrm{mmol} / \mathrm{l}$, respectively. Two waves of follow-up were completed 3.25 and 7 years later, when 1,770 and 1,753 participants, respectively, of the original cohort were reexamined.

The protocol was approved by the Ethics Committee of the Centro de Estudios en Diabetes, Centro de Investigacion en Salud Poblacional, Instituto Nacional de Salud Publica, Mexico City. All participants gave informed consent.

Anthropometric measurements Diabetes in at least one parent or sib was classified as a positive family history of diabetes. Height, weight, waist and hip circumferences, and systolic and diastolic blood pressure were measured as described elsewhere [13].

Biochemical measurements Blood samples were obtained in the fasting state and $2 \mathrm{~h}$ after a standard $75 \mathrm{~g}$ oral glucose load. Serum samples were centrifuged at $1,500 \times \mathrm{g}$, divided into aliquots and stored at $-70^{\circ} \mathrm{C}$ until assayed. Fasting concentrations of serum insulin, proinsulin, plasma glucose, total cholesterol, LDL-cholesterol, HDL-cholesterol and triacylglycerol, and plasma glucose and insulin concentrations $2 \mathrm{~h}$ after an oral glucose load were determined as described elsewhere [13] at baseline and follow-up.

Statistical analysis Data are presented as mean \pm SD. Categorical variables were compared by the $\chi^{2}$ test, 
continuous variables by ANOVA, with Bonferroni-Dunn testing of multiple post hoc comparisons. Logistic regression was carried out by defining response as a diagnosis of diabetes at either of the two follow-up visits and nonresponse as no diabetes at the last visit; results are expressed as OR with 95\% CI. For each continuous variable in a multiple model, OR was calculated for $1 \mathrm{SD}$ of the population value of that variable, in order to compare the relative importance of the variables. The PAR (\%) was calculated as: $100\langle f(\mathrm{RR}-1) /\{1+[f(\mathrm{RR}-1)]\}\rangle$, where $f$ is the prevalence of a given condition and $R R$ is the relative risk of incident diabetes for that condition. When using a multi-level nominal variable for the five mutually exclusive categories of glucose intolerance, a binomial regression model with log-link function was used. For these RRs, PAR was calculated according to the following formula:

$\mathrm{PAR}_{i}=p_{i}\left(\mathrm{RR}_{i}-1\right) /\left[1+\Sigma_{j} p_{j}\left(\mathrm{RR}_{j}-1\right)\right], i=1, \ldots, 5$

The corresponding 95\% CIs were computed using bootstrap sampling (10,000 replicates) [14]. Log-binomial regression and bootstrap estimation were performed using Stata 8 (StataCorp (2005) Stata Statistical Software: Release 8; StataCorp, College Station, TX, USA). For individual categories of glucose intolerance $(2 \times 2$ tables), PAR and CI were calculated using $R 2.8 .0$ statistical software [15]. Receiver operating characteristic (ROC) analysis was carried out by standard methods. A $p$ value $\leq 0.05$ was considered statistically significant.

\section{Results}

In this relatively young population (mean age 47 years) with a high prevalence of diabetes (13.8\% at baseline), IGT was also very prevalent $(13.7 \%)$, five times more so than $\mathrm{IFG}_{6.1}(2.4 \%)$. Of participants with $\mathrm{IFG}_{6.1}, 60 \%$ also had IGT, whereas only $11 \%$ of those with IGT also had $\mathrm{IFG}_{6.1}$.

The RR of diabetes was 4.01 (95\% CI: 3.12-5.14) for participants with IGT and 3.73 (95\% CI: 2.18-6.39) for those with $\mathrm{IFG}_{6.1}$, corresponding to a PAR of 29 (95\% CI: 26-32) and $6 \%(95 \% \mathrm{CI}: 5-7)$, respectively. With the glucose threshold for IFG set at $5.6 \mathrm{mmol} / 1$ instead of $6.1 \mathrm{mmol} / \mathrm{l}$, the new IFG group ( $\mathrm{IFG}_{5.6}$ ) counted 176 individuals, for whom the RR of diabetes was 4.28 (95\% CI: 3.21-5.71) and the corresponding PAR 23\% (95\% CI: 20-25).

When considering the six mutually exclusive combinations of fasting and $2 \mathrm{~h}$ plasma glucose concentrations (Fig. 1), the clinical phenotype of participants who do not have normal glucose tolerance (NGT) was generally similar, all dysglycaemic groups being older, heavier, hyperinsulinaemic, hyperproinsulinaemic and dyslipidae-

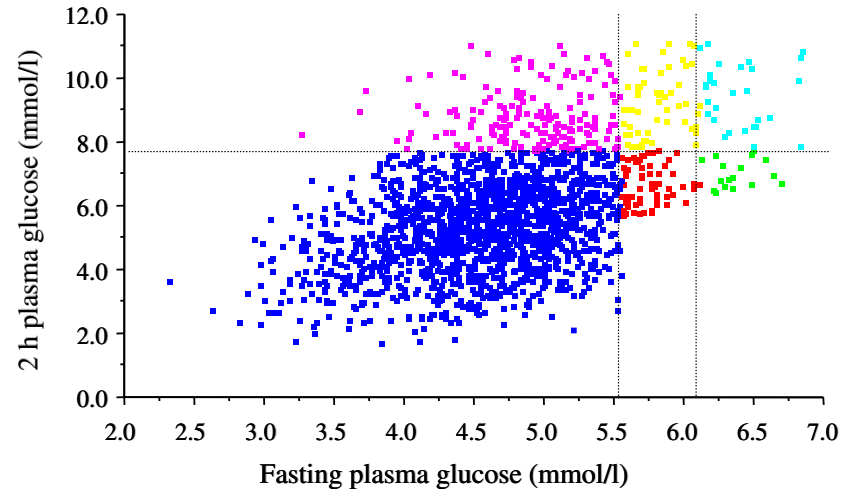

Fig. 1 Individual fasting and $2 \mathrm{~h}$ plasma glucose concentrations in the non-diabetic segment of the Mexico City Diabetes Study population. The $2 \mathrm{~h}$ glucose threshold $(7.8 \mathrm{mmol} / \mathrm{l})$ and the two fasting glucose thresholds (5.6 and $6.1 \mathrm{mmol} / \mathrm{l})$ identify six mutually exclusive (dotted lines) categories of glucose tolerance. Pink, iIGT; yellow, $\mathrm{iIGT}_{5.6}$; blue, $\mathrm{iIGT}_{6.1}$; dark blue, $\mathrm{NGT}$; red, $\mathrm{iIFG}_{5.6}$; green, $\mathrm{iIFG}_{6.1}$

mic (raised triacylglycerols, reduced HDL-cholesterol) compared with the NGT group (Table 1).

Over 7 years of follow-up, 165 participants developed type 2 diabetes (crude incidence rate $1.34 \%$ per year). As shown in Table 2, 39\% of incident diabetes originated from individuals with $2 \mathrm{~h}$ plasma glucose levels $\geq 7.8 \mathrm{mmol} / \mathrm{l}$, while $27 \%$ derived from participants with IFG. Of the latter, however, more than two thirds also had IGT, isolated forms of IFG contributing only $7 \%$ to all incident diabetes cases. The majority of diabetes converters originated from the pool of NGT individuals.

The RR of incident diabetes in participants with isolated IFG $_{6.1}$ was not significantly increased compared with that of NGT participants, while in those with isolated $\mathrm{IFG}_{5.6}$ the risk was threefold increased and similar to that of participants with isolated IGT. Relative risk was further increased (six- to sevenfold) in participants with non-isolated IGT, regardless of whether their fasting glucose was 5.6 to 6.1 or 6.1 to $6.9 \mathrm{mmol} / 1$ (Fig. 2). The corresponding PARs are plotted in Fig. 3.

In a multiple logistic model adjusting for sex, age, familial diabetes and BMI, fasting and $2 \mathrm{~h}$ plasma glucose concentrations (as continuous variables) were independent predictors of incident diabetes, with a somewhat higher OR for $2 \mathrm{~h}$ than for fasting glucose (Fig. 4) and an area under the ROC curve for this model of $79.5 \%$. When the same model was run with tertiles of fasting and $2 \mathrm{~h}$ glucose simultaneously, only the top tertile of fasting glucose carried a significant independent risk of diabetes, whereas the two top tertiles of $2 \mathrm{~h}$ glucose conveyed increasing risk. A fasting glucose between 5.0 and $6.8 \mathrm{mmol} / \mathrm{l}$ was associated with a similar risk to that from $2 \mathrm{~h}$ glucose between 6.4 and $11.1 \mathrm{mmol} / \mathrm{l}$. When fasting and $2 \mathrm{~h}$ glucose were replaced by the multilevel categorical variable describing the five mutually exclusive categories of glucose 
Table 1 Clinical phenotype in participants belonging to six mutually exclusive categories of baseline glucose tolerance

\begin{tabular}{|c|c|c|c|c|c|c|}
\hline Characteristic & NGT & $\mathrm{ilFG}_{5.6}$ & $\mathrm{iIFG}_{6.1}$ & iIGT & $\mathrm{IGT}_{5.6}$ & $\mathrm{IGT}_{6.1}$ \\
\hline$n(\%)$ & $1,594(82.1)$ & $65(3.3)$ & $17(0.9)$ & $179(9.2)$ & $57(2.9)$ & $29(1.5)$ \\
\hline Sex (women/men), $n$ & $912 / 682$ & $44 / 21$ & $13 / 4$ & $115 / 64$ & $35 / 22$ & $15 / 14$ \\
\hline Familial diabetes $(\%)^{\mathrm{a}}$ & 30 & 45 & 27 & 39 & 37 & 41 \\
\hline Age (years) ${ }^{\mathrm{a}}$ & $46 \pm 8$ & $47 \pm 8$ & $49 \pm 8$ & $48 \pm 8^{\mathrm{b}}$ & $50 \pm 8^{\mathrm{b}}$ & $50 \pm 7$ \\
\hline BMI $\left(\mathrm{kg} / \mathrm{m}^{2}\right)^{\mathrm{a}}$ & $27.6 \pm 4.2$ & $29.1 \pm 4.2$ & $29.5 \pm 5.1$ & $29.6 \pm 3.9^{\mathrm{b}}$ & $29.5 \pm 4.5^{\mathrm{b}}$ & $30.5 \pm 5.5^{\mathrm{b}}$ \\
\hline Waist $(\mathrm{cm})^{\mathrm{a}}$ & $95 \pm 12$ & $100 \pm 17^{\mathrm{b}}$ & $100 \pm 11$ & $100 \pm 11^{\mathrm{b}}$ & $102 \pm 12^{\mathrm{b}}$ & $102 \pm 12^{\mathrm{b}}$ \\
\hline Fasting glucose $(\mathrm{mmol} / \mathrm{l})^{\mathrm{a}}$ & $4.53 \pm 0.56$ & $5.73 \pm 0.14^{\mathrm{b}}$ & $6.38 \pm 0.16^{\mathrm{b}}$ & $4.91 \pm 0.41^{\mathrm{b}}$ & $5.80 \pm 0.17^{\mathrm{b}}$ & $6.39 \pm 0.23^{b}$ \\
\hline $2 \mathrm{~h}$ glucose $(\mathrm{mmol} / \mathrm{l})^{\mathrm{a}}$ & $5.27 \pm 1.28$ & $6.66 \pm 0.62^{\mathrm{b}}$ & $7.02 \pm 0.44^{\mathrm{b}}$ & $8.82 \pm 0.84^{\mathrm{b}}$ & $9.27 \pm 0.98^{\mathrm{b}}$ & $9.48 \pm 0.97^{\mathrm{b}}$ \\
\hline Fasting insulin $(\mathrm{pmol} / \mathrm{l})^{\mathrm{a}}$ & $88 \pm 82$ & $102 \pm 64$ & $134 \pm 108$ & $116 \pm 83^{b}$ & $135 \pm 139^{\mathrm{b}}$ & $145 \pm 76^{\mathrm{b}}$ \\
\hline $2 \mathrm{~h}$ insulin $(\mathrm{pmol} / \mathrm{l})^{\mathrm{a}}$ & $501 \pm 429$ & $638 \pm 432^{\mathrm{b}}$ & $756 \pm 688$ & $1,021 \pm 620^{\mathrm{b}}$ & $867 \pm 563^{b}$ & $865 \pm 544^{\mathrm{b}}$ \\
\hline Proinsulin $(\mathrm{pmol} / \mathrm{l})^{\mathrm{a}}$ & $10 \pm 8$ & $12 \pm 10$ & $16 \pm 13$ & $15 \pm 13^{\mathrm{b}}$ & $17 \pm 13^{\mathrm{b}}$ & $29 \pm 20^{\mathrm{b}}$ \\
\hline Triacylglycerol $(\mathrm{mmol} / \mathrm{l})^{\mathrm{a}}$ & $2.29 \pm 1.62$ & $2.44 \pm 1.24$ & $1.84 \pm 0.86$ & $3.10 \pm 2.14^{\mathrm{b}}$ & $2.61 \pm 1.04^{\mathrm{b}}$ & $3.13 \pm 2.16^{\mathrm{b}}$ \\
\hline LDL-cholesterol (mmol/1) & $3.03 \pm 1.03$ & $3.34 \pm 1.18$ & $3.36 \pm 1.08$ & $3.09 \pm 1.26$ & $3.12 \pm 0.81$ & $3.05 \pm 1.02$ \\
\hline HDL-cholesterol $(\mathrm{mmol} / \mathrm{l})^{\mathrm{a}}$ & $0.87 \pm 0.24$ & $0.80 \pm 0.19$ & $0.95 \pm 0.23$ & $0.83 \pm 0.23$ & $0.85 \pm 0.21$ & $0.82 \pm 0.22$ \\
\hline Systolic BP $(\mathrm{mmHg})^{\mathrm{a}}$ & $116 \pm 17$ & $118 \pm 16$ & $120 \pm 15$ & $121 \pm 16^{\mathrm{b}}$ & $128 \pm 18^{\mathrm{b}}$ & $128 \pm 21^{\mathrm{b}}$ \\
\hline Diastolic BP $(\mathrm{mmHg})^{\mathrm{a}}$ & $72 \pm 10$ & $75 \pm 9$ & $71 \pm 8$ & $76 \pm 11^{\mathrm{b}}$ & $76 \pm 11^{\mathrm{b}}$ & $78 \pm 13^{\mathrm{b}}$ \\
\hline
\end{tabular}

Unless otherwise stated, data are mean $\pm \mathrm{SD}$

${ }^{\mathrm{a}} p \leq 0.05$ by ANOVA; ${ }^{\mathrm{b}} p \leq 0.05$ vs NGT by Bonferroni-Dunn test

intolerance (Fig. 1), the area under the ROC curve was 77.3\%. An expanded model of incident diabetes included serum proinsulin levels and diastolic blood pressure as independent, positive predictors and $2 \mathrm{~h}$ plasma insulin concentrations and HDL-cholesterol levels as negative predictors (Fig. 5).

\section{Discussion}

The present analysis demonstrates that: (1) when glucose concentration is used as a continuous variable, both fasting and post-load plasma glucose predict incident diabetes independently of other predictors and of one another; (2) the clinical phenotypes of IFG and IGT are generally similar; (3) isolated $\mathrm{IFG}_{6.1}$ is not a diabetes risk condition; (4) lowering the diagnostic threshold for IFG from 6.1 to
$5.6 \mathrm{mmol} / \mathrm{l}$ substantially raises $\mathrm{RR}$ and PAR; and (5) performing an OGTT captures substantially more diabetes progressors than those identified by $\mathrm{IFG}_{5.6}$. These conclusions need to be seen in context.

Several previous studies have reported on the predictive role of fasting or post-load glucose levels for incident type 2 diabetes, but the two have rarely been assessed together and after controlling for other strong predictors (age, BMI and familial diabetes) $[4,5]$. The present analysis shows that an equivalent (i.e. $1 \mathrm{SD}$ of the population distribution) change in fasting and $2 \mathrm{~h}$ glucose levels is associated with a 45 and $87 \%$ increased risk of diabetes, respectively 7 years later (Fig. 4). From the pathophysiological standpoint, it is hardly surprising that both glucose measures should be predictive independently of one another. In fact, fasting glucose is regulated by endogenous glucose output, under the dual control of pre-hepatic plasma insulin and glucagon
Table 2 Participants developing diabetes over 7 years in six mutually exclusive categories of baseline glucose tolerance

\begin{tabular}{|c|c|c|c|c|}
\hline \multirow[t]{2}{*}{$2 \mathrm{~h}$ glucose } & \multicolumn{4}{|c|}{ Fasting glucose } \\
\hline & $<5.6 \mathrm{mmol} / 1$ & $<6.1 \mathrm{mmol} / 1$ & $\geq 6.1 \mathrm{mmol} / 1$ & Total \\
\hline$<7.8 \mathrm{mmol} / \mathrm{l}(n)$ & 1,594 & 65 & 17 & 1,676 \\
\hline Developing diabetes $(n)$ & 89 & 11 & 1 & \\
\hline Percentage & 5.6 & 16.9 & 0.1 & \\
\hline$\geq 7.8 \mathrm{mmol} / \mathrm{l}(n)$ & 179 & 57 & 29 & 265 \\
\hline Developing diabetes $(n)$ & 31 & 21 & 12 & \\
\hline Percentage & 17.3 & 36.8 & 41.4 & \\
\hline Total $(n)$ & 1,773 & 122 & 46 & 1,941 \\
\hline
\end{tabular}




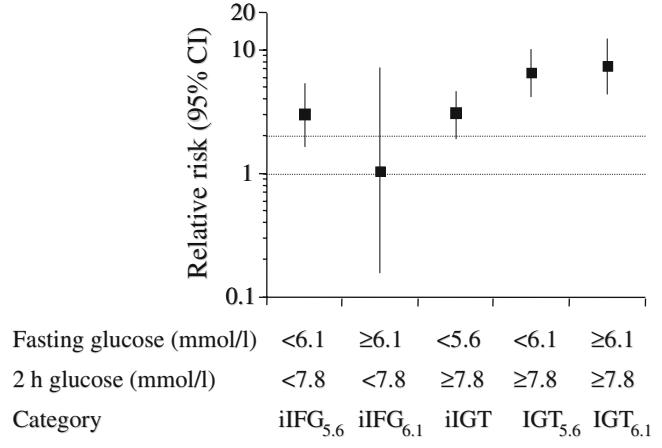

Fig. 2 Relative risk of developing diabetes in five mutually exclusive categories of glucose intolerance. Risk ratios (plotted on a log scale) are relative to the risk in NGT individuals

levels, and by fasting glucose clearance (mostly by noninsulin-dependent tissues) [16]. In contrast, $2 \mathrm{~h}$ plasma glucose levels are principally the result of glucose-induced insulin secretion (in particular, beta cell glucose sensing) and insulin-stimulated glucose clearance [17]. Suppression of endogenous glucose output during the post-glucose period, i.e. hepatic insulin sensitivity, also contributes to limitation of glucose excursions. In addition, as repeatedly demonstrated by studies employing the euglycaemichyperinsulinaemic clamp technique coupled with glucose tracers, hepatic and peripheral tissue (mainly skeletal muscle) sensitivity to insulin are correlated with one another across a range of conditions [18]. This correlation is consistent with the fact that fasting and $2 \mathrm{~h}$ glucose concentrations are also intercorrelated (with a coefficient of determination of $62 \%$ in the present study population). As a result, any prognostic criterion for type 2 diabetes based on both plasma glucose measures will translate into either measure alone being predictive and each making an independent contribution to diabetes risk. The fact that post-load glucose values are stronger predictors than fasting levels in this population also reflects the wider variation in the former (twice as wide) than in the latter (coefficient of variation of 30 vs $14 \%$ in our cohort). More specifically, fasting glucose levels in the range 5.0 to $6.8 \mathrm{mmol} / \mathrm{l}$ carry

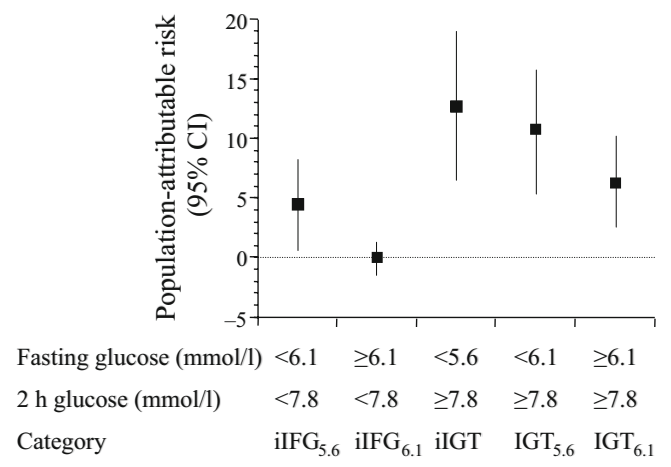

Fig. 3 PAR of developing diabetes in the five mutually exclusive categories of glucose intolerance seen above (Fig. 2)

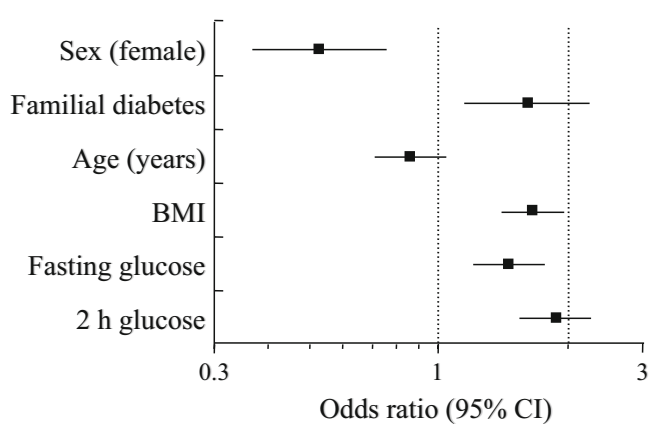

Fig. 4 Multivariate predictive model of incident type 2 diabetes including factors as shown. For continuous variables, odds ratio (plotted on a log scale) was calculated for one standard deviation of each variable

an equivalent predictive power to that of $2 \mathrm{~h}$ glucose levels in the range 4.9 to $6.4 \mathrm{mmol} / \mathrm{l}$, while higher $2 \mathrm{~h}$ values still within the IGT range $(6.4-11.1 \mathrm{mmol} / \mathrm{l})$ are much stronger independent predictors.

The use of threshold values of continuous variables to diagnose clinical conditions is practical and time-honoured. The validity of thresholds hinges upon their relation to endorgan damage, complications or mortality. As epidemiological or clinical trial data accumulate, the identification of thresholds improves in accuracy. What also matters for healthcare purposes is the amount of risk in the general population that can be attributed to predictors (PAR) and, therefore, the fraction of morbidity that can be prevented by intervening on risk factors. The present data show that, with the current definitions of all three forms of glucose intolerance (type 2 diabetes, IGT and IFG), the PAR is approximately fivefold higher for IGT than for IFG. As expected, if the IFG threshold is decreased by $9 \%$ (from 6.1 to $5.6 \mathrm{mmol} / \mathrm{l}$ ), the PAR rises considerably. However, even with a lower threshold, $\mathrm{IFG}_{5.6}$ as such accounts for only $19 \%$ of diabetes progressors, a much larger proportion $(\sim 40 \%)$ being derived from individuals with IGT. On the other hand, if the same decrement were applied to the IGT

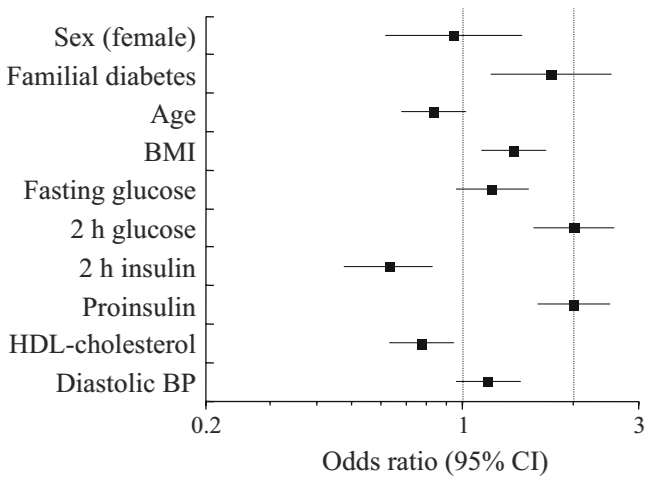

Fig. 5 Expanded predictive model of incident type 2 diabetes $(2 \mathrm{~h}$ plasma insulin and fasting proinsulin concentrations log-transformed). Odds ratios are plotted on a log scale 
lower threshold (from 7.8 to $7.1 \mathrm{mmol} / \mathrm{l}$ ), the PAR would rise to $34 \%$ (95\% CI: $30-38$ ), i.e. one-third of the total population risk. These calculations, derived as they are from population-based, longitudinal observations in an ethnic group with a rather high diabetes prevalence, serve the sole purpose of providing an objective platform upon which policy decisions should rest. Thus, no single test or threshold is best under all circumstances and for all purposes. If the goal is to extract from the general population as many individuals at risk as possible, then the relevant variable is the PAR. IFG $_{5.6}$ and IGT would have roughly equivalent sensitivity, the former being a cheaper tool than the latter. If, on the other hand, the objective is to capture persons at high risk with good specificity, then use of a combined criterion (isolated IGT [iIGT]) would maximise RR and PAR relative to the background population (Figs 2 and 3). The final choice must weigh these operating characteristics against such factors as cost, logistics and healthcare agenda. In this respect, 'isolated' forms are only of scientific interest (and modest at that).

In a population-based study of 1,342 Dutch participants with a mean age of 60 years, de Vegt et al. [19] also reported similar RR for patients with IGT and $\mathrm{IFG}_{6.1}$ to develop diabetes over 6 years; overlap between the two dysglycaemic states was not, however, analysed, nor was PAR reported; the phenotypic characterisation only included anthropometrics and blood pressure values.

One important finding in our study was that high-risk individuals, be they IFG or IGT by any definition, share a common clinical phenotype, with only minor differences (Table 1). As a result, in an expanded prediction model (Fig. 5), higher serum proinsulin and diastolic blood pressure levels confer additional independent risk (45 and $19 \%$, respectively, for each SD of their population values), while higher serum HDL-cholesterol and $2 \mathrm{~h}$ post-glucose plasma insulin levels independently reduce (by $26 \%$ ) risk of incident diabetes. Again, known pathophysiology underlies these stochastic features. Thus, high serum proinsulin concentrations are reputed to stand for early beta cell dysfunction (incomplete processing of proinsulin to insulin) [20]; hypertension co-segregates with manifest diabetes and higher blood pressure levels co-track insulin resistance [21]; low HDL-cholesterol concentrations cluster with insulin resistance [22]; and lower post-load plasma insulin levels have been shown to predict and precede onset of diabetes in the Mexico City population [23]. Therefore, a screening algorithm for diabetes risk could include not only anthropometric but also other traits of the prediabetic state, with or without [24], plasma glucose measures.

Duality of interest The authors declare that there is no duality of interest associated with this manuscript.

\section{References}

1. Stratton IM, Adler AI, Neil HA et al (2000) Association of glycaemia with macrovascular and microvascular complications of type 2 diabetes (UKPDS 35): prospective observational study. BMJ 321:405-412

2. Expert Committee on the Diagnosis and Classification of Diabetes Mellitus (2000) Report of the Expert Committee on the Diagnosis and Classification of Diabetes Mellitus (Position Statement). Diabetes Care 23(Suppl 1):S4-S19

3. Unwin N, Shaw J, Zimmet P, Alberti KG (2002) Impaired glucose tolerance and impaired fasting glycaemia: the current status on definition and intervention. Diabet Med 19:708-723

4. Abdul-Ghani MA, Williams K, DeFronzo R, Stern M (2006) Risk of progression to type 2 diabetes based on relationship between postload plasma glucose and fasting plasma glucose. Diabetes Care 29:1613-1618

5. Rasmussen SS, Glümer C, Sandbaek A, Lauritzen T, BorchJohnsen K (2008) Determinants of progression from impaired fasting glucose and impaired glucose tolerance to diabetes in a high-risk screened population: 3 year follow-up in the ADDITION study, Denmark. Diabetologia 51:249-255

6. DECODE Study Group, the European Diabetes Epidemiology Group (2001) Glucose tolerance and cardiovascular mortality: comparison of fasting and 2-hour diagnostic criteria. Arch Intern Med 161:397-405

7. Pankow JS, Kwan DK, Duncan BB et al (2007) Cardiometabolic risk in impaired fasting glucose and impaired glucose tolerance: the Atherosclerosis Risk in Communities Study. Diabetes Care 30:325-331

8. Ferrannini E, Gastaldelli A, Miyazaki Y et al (2003) Predominant role of reduced beta-cell sensitivity to glucose over insulin resistance in impaired glucose tolerance. Diabetologia 46:1211-1219

9. World Health Organization (1999) Definition, diagnosis and classification of diabetes mellitus and its complications: Report of a WHO Consultation. Part 1: Diagnosis and classification of diabetes mellitus. WHO, Geneva

10. Nathan DM, Davidson MB, DeFronzo RA et al (2007) Impaired fasting glucose and impaired glucose tolerance. Implications for care. Diabetes Care 30:753-759

11. Genuth S, Alberti KG, Bennett P et al (2003) Expert Committee on the Diagnosis and Classification of Diabetes Mellitus: followup report on the diagnosis of diabetes mellitus. Diabetes Care 26:3160-3167

12. Forouhi NG, Balkau B, Borch-Johnsen K et al (2006) The threshold for diagnosing impaired fasting glucose: a position statement by the European Diabetes Epidemiology Group. Diabetologia 49:822-827

13. Nannipieri M, Gonzales C, Baldi S et al (2005) Liver enzymes, the metabolic syndrome, and incident diabetes: the Mexico City diabetes study. Diabetes Care 28:1757-1762

14. Efron B, Tibshirani RJ (1993) An introduction to the bootstrap. Chapman and Hall, New York

15. Development Core Team (2006) R: A language and environment for statistical computing. Foundation for Statistical Computing, Vienna. Available from http://www.R-project.org, accessed 1 November 2008

16. DeFronzo RA, Ferrannini E (1997) Insulin actions in vivo: Glucose metabolism. In: Alberti KGMM, DeFronzo RA, Keen $\mathrm{H}$, Zimmet $\mathrm{P}$ (eds) International textbook of diabetes mellitus, 2nd edn. Wiley, New York, pp 505-530

17. Ferrannini E, Gastaldelli A, Miyazaki Y, Matsuda M, Mari A, DeFronzo RA (2005) beta-Cell function in subjects spanning the range from normal glucose tolerance to overt diabetes: a new analysis. J Clin Endocrinol Metab 90:493-500 
18. Natali A, Toschi E, Camastra S, Gastaldelli A, Groop L, Ferrannini E (2000) Determinants of postabsorptive endogenous glucose output in non-diabetic subjects. European Group for the Study of Insulin Resistance (EGIR). Diabetologia 43:1266-1272

19. de Vegt F, Dekker JM, Jager A et al (2001) Relation of impaired fasting and postload glucose with incident type 2 diabetes in a Dutch population. JAMA 285:2109-2113

20. Porte D Jr, Kahn SE (1989) Hyperproinsulinemia and amyloid in NIDDM. Clues to etiology of islet beta-cell dysfunction? Diabetes 38:1333-1336

21. Ferrannini E (1995) The phenomenon of insulin resistance: its possible relevance to hypertensive disease. In: Laragh JH, Brenner
BM (eds) Hypertension: pathophysiology, diagnosis, and management, 2nd edn. Raven, New York, pp 2281-2300

22. Jeppesen J, Facchini FS, Reaven GM (1998) Individuals with high total cholesterol/HDL cholesterol ratios are insulin resistant. J Intern Med 243:293-298

23. Ferrannini E, Nannipieri M, Williams K, Gonzales C, Haffner SM, Stern MP (2004) Mode of onset of type 2 diabetes from normal or impaired glucose tolerance. Diabetes 53:160 165

24. Colagiuri S, Borch-Johnsen K, Wareham NJ (2008) Back to the future-Do IGT and IFG have value as clinical entities? Diab Res Clin Pract 81:131-133 